Copyright (C) 2020 University of Bucharest Printed in Romania. All rights reserved

ISSN print: $1224-5984$

ISSN online: $2248-3942$
Rom Biotechnol Lett. 2020; 25(1): 1260-1266

doi: $10.25083 / \mathrm{rbl} / 25.1 / 1260.1266$

Received for publication, June, 12, 2018

Accepted, August, 14, 2018

Original paper

\title{
Comparative evaluation of nutritional and quality factors of pork meat products obtained traditionally in Romania and in the industrial system
}

\author{
OANA REGET ${ }^{*}$, IONUŢ CORDIŞ ${ }^{1}$, SORIN DANIEL DAN ${ }^{1}$, MARIAN MIHAIU ${ }^{1}$, \\ FLAVIU TĂBĂRAN ${ }^{2}$, ALEXANDRA TĂBĂRAN ${ }^{1}$
}

${ }^{1}$ Animal Breeding and Food Safety Department, Faculty of Veterinary Medicine, University of Agricultural Sciences and Veterinary Medicine, Manastur street no. 3/5, Cluj-Napoca, Romania

${ }^{2}$ Pathologic Anatomy Department, Faculty of Veterinary Medicine, University of Agricultural Sciences and Veterinary Medicine, Manastur street no. 3/5, Cluj-Napoca, Romania

\begin{abstract}
Pork meat and products are the first in the rankings of consumer's preferences in Romania. In the light of this fact, we performed a complex assessment based on histological and chemical examination of the structural differences in the traditional pork products compared to industrial products.

Our study reveald that traditional pork meat products can be considered as food of superior biological value by higher protein, fat, collagen and lower water content compared to other pork products processed in the industrial system. Also, from the histological point of view of pork products obtained in the industrial system are characterized by a hyperhydration general aspect of the cell with an increase in the amount of the interstitial fluid. Comparative evaluation of processed pork products in two different systems (traditional and industrial) revealed an increased content of fibrous tissue and interstitial fluid for the industrial one in comparisson with the one obtained in the traditional system.
\end{abstract}

Keywords Traditional, pork meat products.

To cite this article: REGET O, CORDIŞ I, DAN SD, MIHAIU M, TĂBĂRAN F, TĂBĂRAN A. Comparative evaluation of nutritional and quality factors of pork meat products obtained traditionally in Romania and in the industrial system. Rom Biotechnol Lett. 2020; 25(1): 1260-1266. DOI: $10.25083 / \mathrm{rbl} / 25.1 / 1260.1266$

*Corresponding author: OANA REGET, Animal Breeding and Food Safety Department, Faculty of Veterinary Medicine, University of Agricultural Sciences and Veterinary Medicine, Manastur street no. 3/5, Cluj-Napoca, Romania E-mail: oana.reget@gmail.com 


\section{Introduction}

Romania has a large variations of traditional meat products, that have different ingredients and recepies according to the region. A traditional product can only be manufactured in limited quantities, should be obtained with local raw materials and using a traditional processing, a traditional recipe and must not contain any food additives. Romanians and foreigners have shown, in the past years, an increased interest for this type of products due to the specific sensorial attributes. Moreover, these products are healthy food and are part of the national culture and identity (GHEORGHE \& al [3]). Given the use of local raw material there is a great variability in the quality of traditional products (MORAR \& al [5]). In contrast to these facts, industrial products are obtained in a higher amount and they have standard recipes that use few additives and raw material obtained also industrially.

Chemical methods are frequently used to determine the quality of meat products, but the histological study provides the possibility of detecting tissues directly in meat products (GEORGIER \& al [2]).

Given the facts mentioned above, our study aimed to determine the compositional quality of some certified traditional products compared to similar industrial products, using a chemical and a histological method.

\section{Material and Method}

To determine the compositional quality of traditional products we gathered the samples from a traditionally certified production unit from Sălaj County that raises the pigs in extensive system. The products tested were smoked cured ham $(n=10)$, cured ham $(n=10)$, smoked ham $(n=10)$ and sausages $(\mathrm{n}=10)$ and were collected within a one-month period. For performing a comparative analysis, the same products were purchased from hypermarkets, bearing the label of industrial production companies. All the samples were transferred to the laboratory at $4-6^{\circ} \mathrm{C}$ temperature and their analysis started within 3 hours.

\section{The determination of chemical composition through infrared spectroscopy}

Infrared spectroscopy was performed using the FoodScan Lab analyzer, device used to control the compositional quality in production and it is used for a wide range of food products. It is manufactured and calibrated to analyze raw material and final products with a minimal sample preparation. FoodScan Lab provides a quick and accurate analysis of key parameters such as protein, water, fat and collagen content.

\section{The histological evaluation of the pork meat products obtained in a traditional system compared to those obtained in an industrial system}

Samples taken in the form of fragments up to $0.4 \mathrm{~cm}$ thick were chemically fixed in formalin $10 \%$ (4\% formaldehyde) buffered for 72 hours and then dehydrated by successive dipping in alcohol baths with increasing concentrations $(70,80,95$ and $100 \%)$, clarified in xylene and infiltrated with paraffin (CĂTOI \& al [1]). Finally, the blocks were cut using a rotating microtome (Leica RM), displayed and colored Hematoxylin-Eosin (HE) following the routine protocol of the Histopathology Laboratory of the Pathological Anatomy Discipline, FMV Cluj-Napoca.

\section{Results and Discussions}

The compositional evaluation of traditional products obtained from pork meat from extensive system revealed significant differences compared to pork meat products purchased from hypermarkets. Traditional products are products with specific characteristics but must comply with the minimum quality criteria stated in the legislation.

The results obtained by analyzing the samples using infrared spectroscopy technique are presented in Table 1.

Table 1. The averages of the compositional values revealed at the analysis of the traditional pork products

\begin{tabular}{|c|c|c|c|c|c|}
\hline \multirow{2}{*}{ Product } & \multicolumn{5}{|c|}{ Compositional parameters\% } \\
\cline { 2 - 6 } & Fat content & $\begin{array}{c}\text { Protein } \\
\text { content }\end{array}$ & $\begin{array}{c}\text { Colagen } \\
\text { content }\end{array}$ & Water content & $\begin{array}{c}\text { Protein / Colagen } \\
\text { ratio }\end{array}$ \\
\hline Smoked cured ham & 5.13 & 28.54 & 2.14 & 55.23 & 13.33 \\
\hline Cured ham & 3.14 & 17.33 & 1.82 & 52.66 & 9.52 \\
\hline Smoked ham & 28.99 & 19.08 & 2.14 & 45.13 & 8.91 \\
\hline Smoked sausage & 32.25 & 20.73 & 2.40 & 42.31 & 8.63 \\
\hline
\end{tabular}

As it can be seen (Table 1) the highest mean value for protein was found in the smoked cured ham $(28.54 \%)$, proving that this type of product has in its composition a large amount of muscle tissue that could provide a high nutritional value.

Smoked sausages had an important content of fat $(32.25 \%)$, because of the ingredients used in this traditional product and the reduced time of curing.

The collagen / protein ratio was also high compared to the other analyzed products. According to Health Ministry's Order No. 957/1998 the maximum percentage allowed for the collagen/protein ratio in meat products is $20 \%$, excepting sausages and liver sausages. No one of the analyzed product exceeded this maximum limit.

Comparing with other values reported in the literature for specific traditional products, the findings in our study are better, in terms of quality. Comparing to traditional Swiss or German sausages, the water content is much lower in the samples of sausages we analyzed, with an average of $42.31 \%$, towards $57.8 \%$ and $57 \%$ respectively (SCHMID \& al [6]). 


\section{Evaluation of compositional differences between the traditional products and industrial ones}

When comparing the results obtained in the analysis of traditional pork products with those purchased from hypermarkets, there were significant differences regarding some compositional parameters.
For the product smoked cured ham the most important difference, statistically significant ( $\mathrm{p}<0.05$ ), was found in the content of water and protein, the product purchased in the commercial stores having a higher percentage of water and a lower percentage of proteins, fact that diminishes its nutritional value (Fig. 1).

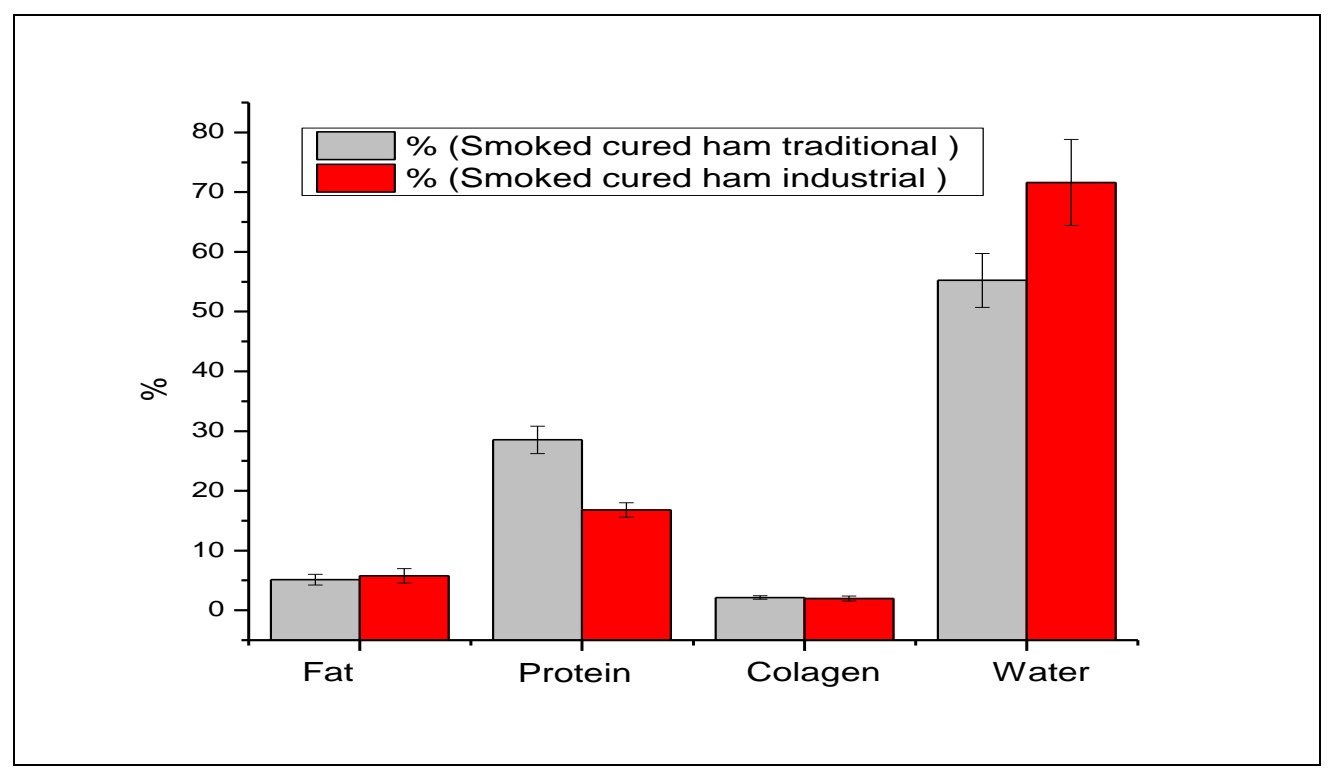

Figure 1. The composition of traditional and industrial smoked cured ham.

As can be seen from Fig. 2, the content of water is again higher for the industrial product compared to the content of water found in the traditional product, also the protein content found in the traditional product is much higher $(24.02 \%)$ than in the industrial product $(16.01 \%)$. These differences are statistically significant $(\mathrm{p}<0.05)$ and it can be stated that the traditional cured ham has a higher nutritional value.

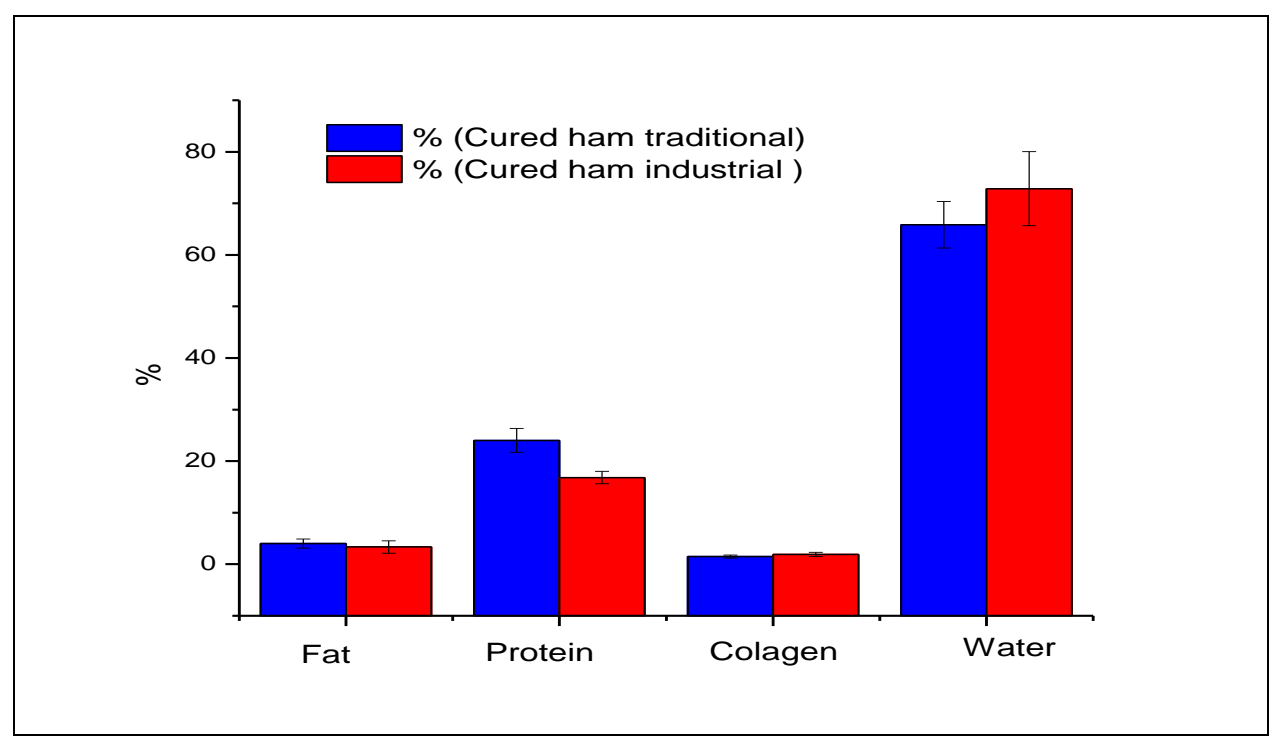

Figure 2. The composition of traditional and industrial cured ham.

In the smoked pork ham product, the differences between industrial and traditional products are obvious, the same as in other cases. As shown in Fig. 3 the water content has the largest variations and the differences being statistically significant $(\mathrm{p}<0.05)$. 


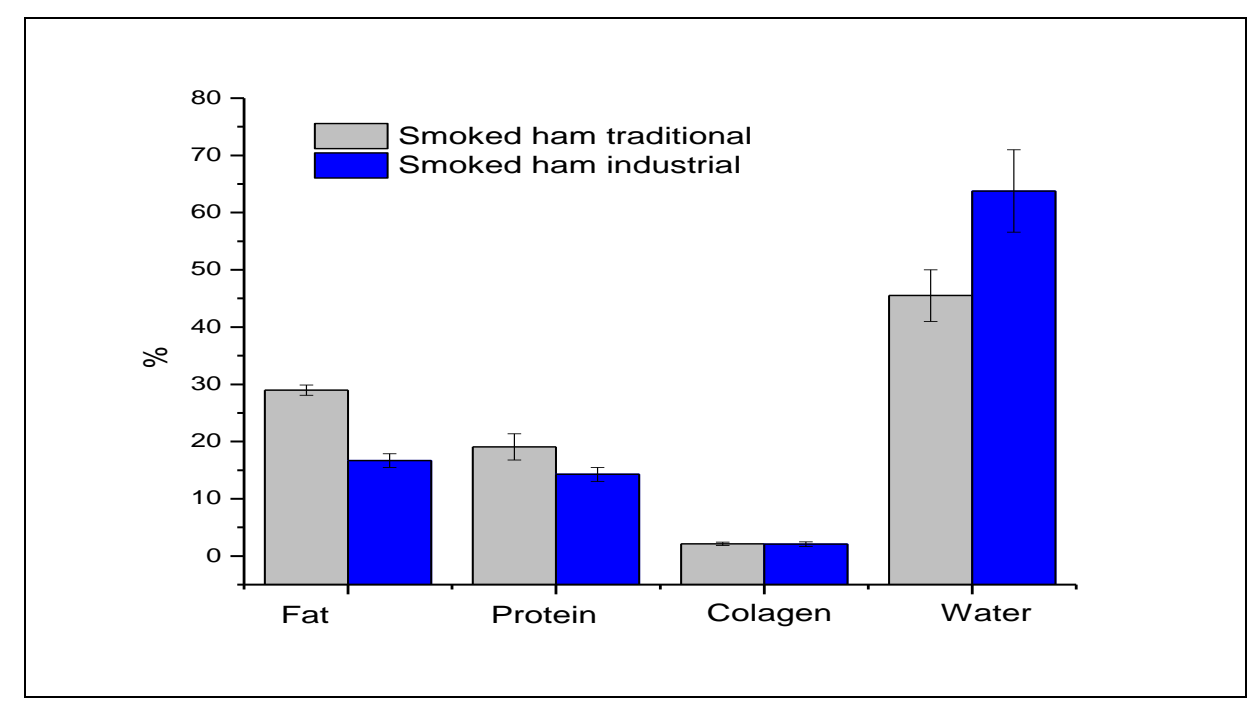

Figure 3. The compositional variation of traditional and industrial smoked ham.

The nutritional quality is also influenced by the higher protein content in the traditional product, the differences being significantly different $(\mathrm{p}<0.05)$.

In the case of the traditional smoked sausage, the compositional values vary statistically $(p<0.05)$ compared to the industrial product. The amount of fat is much higher in the industrial one $(45.14 \%)$ compared to the traditional one $(32.25 \%)$. The protein content is significantly different ( $\mathrm{p}<0.05$ ), comparing the analyzed products, with a higher average value for the traditional product $(20.73 \%)$ towards $16.84 \%$ for the industrial one. It can be concluded that the industrial product found in commercial stores is richer in fat but lower in meat because protein content also depends on the amount of meat used in processing. Also, a significant difference can be noticed in the water content, the highest value being found in the traditional product (42.31\% vs. $33.87 \%)$.

\section{Evaluation of compositional differences between the traditional products and industrial ones through histological examination}

The histological examination method is frequently used to characterize biological tissues at microscopic level, particularly as a tool for controlling the texture of meat in food science. The technique used in the present study has been applied for the first time in Romania on traditional pork products compared to those obtained in the industrial system.

As can be seen from Fig. 4, the differences in the histological examination are quite significant. Thus, in Figure A, the muscle tissue (indicated by the white asterisk) adipose tissue (indicated by the black asterisk) and vegetal tissue (indicated by arrows). Figure B shows the general histological appearance of the product obtained industrially, showing the muscle mixture (indicated by the white asterisk), adipose tissue (indicated by the black asterisk) and vegetal tissue (indicated by arrows); to notice the abundant presence of fibrous tissue (the left side of the image), due to the use of a large quantity of tendons in the composition and thus reveling a low nutritional value of the final product.

Images $\mathrm{C}$ and $\mathrm{D}$ represent comparatively the details of the histological structure of the two products obtained in the traditional and industrial system; the images capture the morphology of vegetal tissue embedded in the blend of muscle fibers and adipose tissue; to note the relatively intact structure of muscle fibers that retains the typical structure (sarcolemma, plasmalemma, multiple nuclei).

Fig. 5 revealed significant structural differences in this product. Thus, in Figure A, the overall histological appearance of the product obtained in a traditional system reveals a well-preserved structure of the skeletal striated muscle (with asterix) muscles surrounded by the perimysium (indicated by the arrow). In comparison with this, at the level of the industrial sample, a poorly preserved histological structure was observed towards to the traditional product. Noteworthy, in image B (industrial sample) was the vacuolated appearance of muscle cells, weak muscle fiber demarcation and low eosinophilia. This reveals a much wider processing at the level of the industrial product, a higher structural modification as a result of water injection, aspects that give these differences from a histological point of view and therefore also from a qualitative point of view, due to a higher content of water, detrimental to muscle fiber, that provides an important nutritional value. 


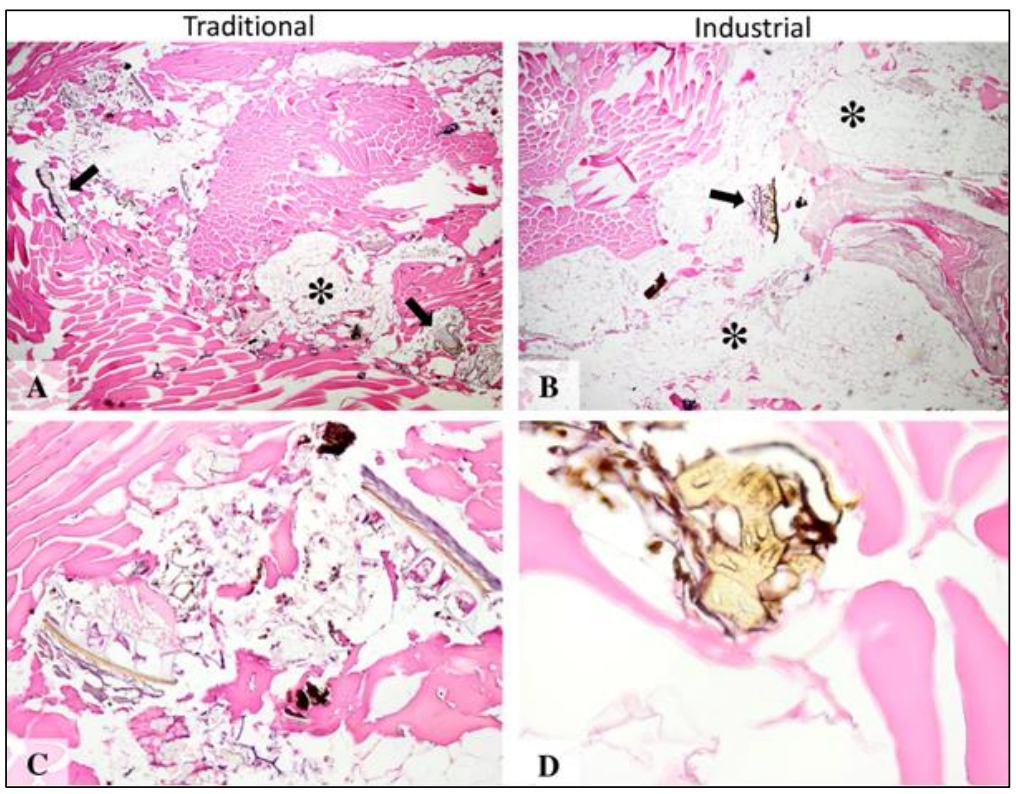

Figure 4. Microscopic structure of the sausages obtained in a traditional system (left column) and industrial system (right column); Staining HE obx 10 (images A and B), obx 40 (image C) and respectively obx100 (image D).

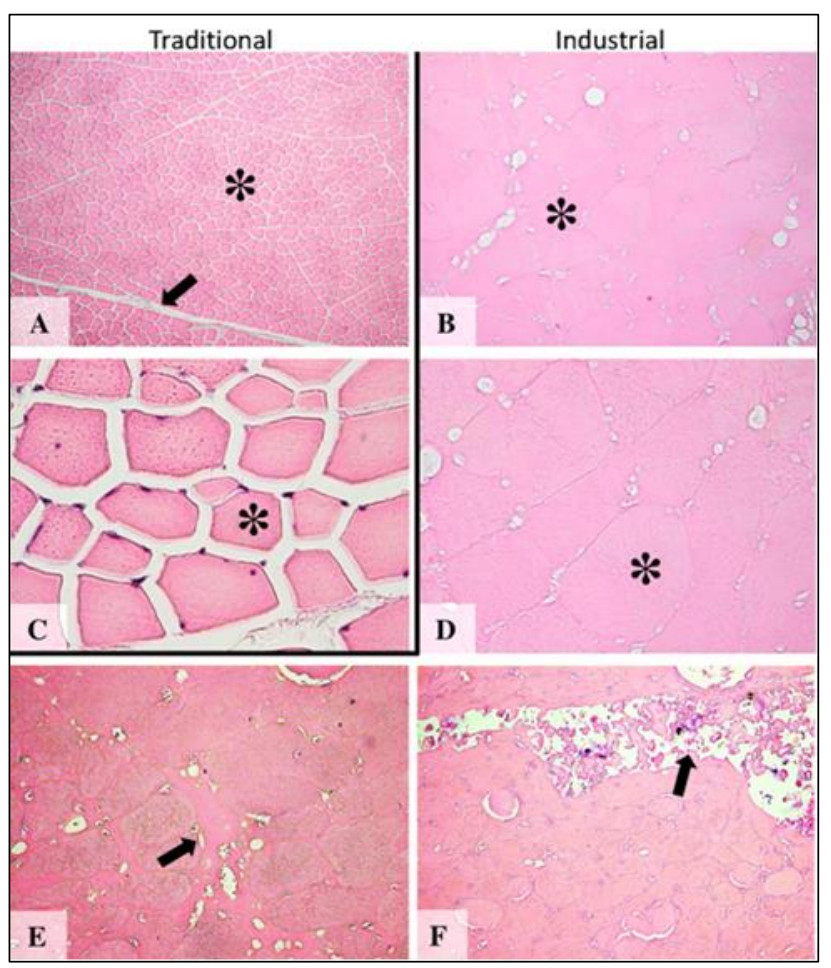

Figure 5. Microscopic structure of smoked cured ham obtained in a traditional system (image A and C) and in an industrial system (image B, D, E and F); HE stainning, obx 10 (image A), obx 20 (images B and F), obx 40 (image E) and respectively obx100 (images $\mathrm{C}$ and D).

In Figure 5, C and D, the histological structures of the two production systems samples can be seen comparatively and in more detail. For the traditional product (Figure C), a rectangular appearance of the myocytes (following the dehydration / drying process of the product) is observed and the intact preservation of the cellular details - the nuclei being clearly visible - peripherally arranged with the highlighting of a fine eosinophilic striped sarcoplasm. For the product obtained in the industrial system (Figure D) the diameter and rounded edge of myocytes (hyperhydration probably due to the water injection process from the technological flow of this product) and the eosinophilic, 
vacuolated appearance of the peripheral fluid are observed. To highlight is the poor keeping of morphology, the absence of nuclei and the fragmentation of sarcoplasm in the industrial sample.

Images $\mathrm{E}$ and $\mathrm{F}$ of Fig. 5 present histological structural details of the industrial product, highlighting the tissue hyperhydration, the paste injection zones (the arrow in the F image) as well as the interstitial fluid (eosinophilic, vacuolated) appearance being abundantly in image $\mathrm{E}$.

Figure 6 shows the comparative histological aspects between the traditional pork ham and the same product range obtained on industrial system. The histological images obtained revealed distinct aspects between the two products such as in Figure A, representing a longitudinal section the well-kept structure of skeletal muscle (asterisk) surrounded by perimysium (indicated by the arrow) and in Figure B - cross-sectional view of the general appearance of the industrial product showing the muscle tissue (indicated by asterisk) and the redline corresponding to the injection area of the paste (indicated by the arrow).

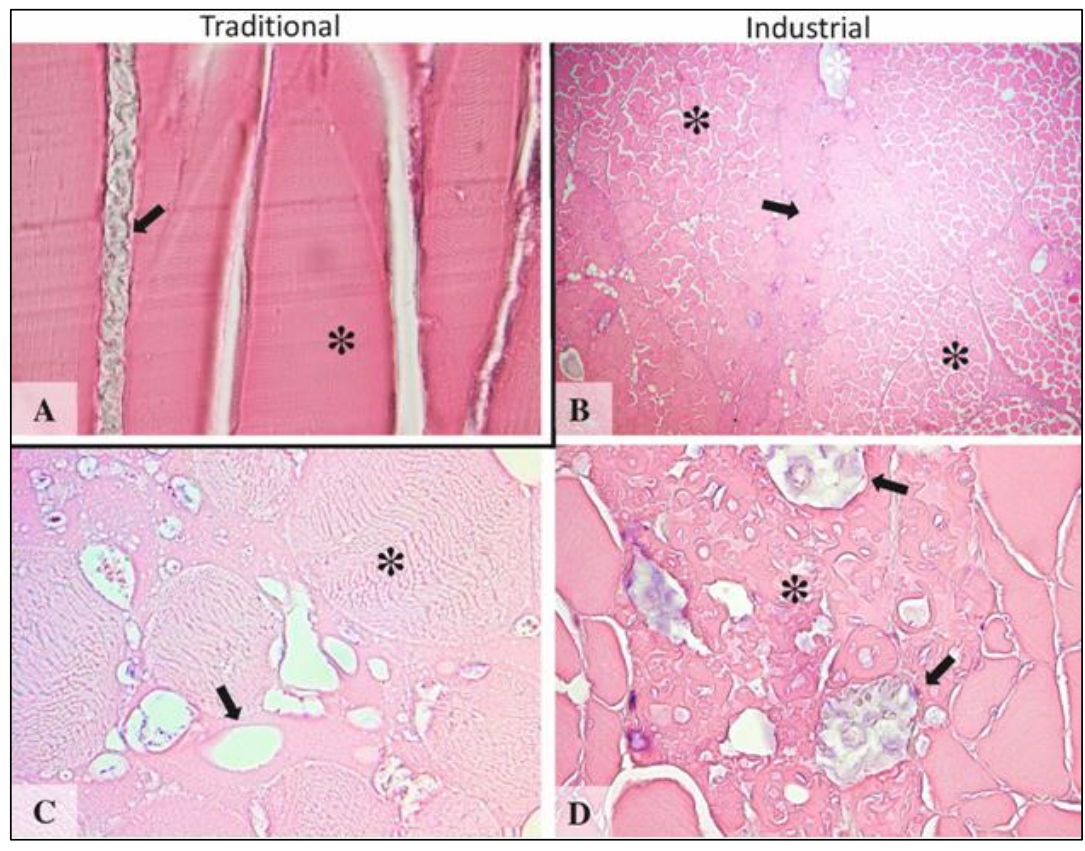

Figure 6. Microscopical structure of the smoked ham product obtained in a traditional system (image A) and in an industrial system (images B, C and D); Stainning HE, ob x 10 (image B) and respectively ob x 100 (images A, C and D).

Images $\mathrm{C}$ and $\mathrm{D}$ represent the histological structural details of the industrial product, showing the tissue hyperhydration, the paste injection path (D asterisk) as well as the interstitial fluid (eosinophilic, vacuolized) appearance present abundantly in Figure C. Morphologically injected D image is present as an eosinophilic acellular mass with heterogeneous granules (some of which are of plant origin-indicated by arrow). It is worth noting the myocytes hyperhydration from the $\mathrm{C}$ picture, the weak eosinophilic appearance of the sarcoplasm and the large distance between the myocytes striations.

Our research, regarding the histological characterization of the transformations that take place due to different processes used for obtaining pork meat products was achieved for the first time in Romania. Scientific literature only reveals data on the application of hematoxylin and eosin method by Latorre et al (LATORRE $\&$ al [4]) to detect the meat content in processed meat products and their evaluation showed unpermitted tissues like soy, cartilage, gizzard, ovary, lymph node, and glandular tissues. Other studies carried out in the United States showed the presence of bone, collagen, blood vessels, peripheral nerves, adipose, cartilage, and skin tissues as well as plant materials, in products like hamburgers and hotdogs.

Studies regarding the histological structure of some traditional Lithuanian sausages revealed differences in the amount of skeletal muscles, adipose and connective tissues in the samples collected from two different producers that had the same type of product (LATORRE $\&$ al [4]).

\section{Conclusions}

In conclusion, to our knowledge, this is the first study reporting the differences regarding the compositional and nutritional value of traditionally and industrially obtained meat products in Romania, which correlates results obtained by infrared spectroscopy and histomorphological 
assessment. Traditional pork meat products can be considered as food of superior biological value by higher protein, fat, collagen and lower water content compared to other pork products processed in the industrial system, also the histological point of view, the products obtained in the industrial system are characterized by a generalized aspect of cellular hyperhydration with an increased amount of interstitial fluid. The comparative histological assessment of pork meat products processed in two different systems (traditional and industrial) revealed a significant growth in fibrous tissue and interstitial fluid for those from the industrial system.

\section{References}

1. CAtOI C., M. TAUlescU, A. GAL, P. BOlFĂ, F. TĂBĂRAN, A. NAGY, G. BORZA, RALUCA VIDRIGHINESCU, ALEXANDRA IRIMIE, ROXANA CORA - Tehnici de anatomie patologică veterinară. Editura Academic Pres, Cluj-Napoca, 2014, pp. 98-105.
2. GEORGIER L., S. VITANOV, Adulteration of mince and sausages, Khranitelana Promish Lenost., 44(1): 15-16, (1995).

3. GHEORGHE G., B.G. NISTOREANU, ALINA FILIP, Traditional products - vectors of sustainable development on the regional and national markets, Amfiteatru Economic, 15, pp. 645-658 (2013).

4. LATORRE R., J. SADEGHINEZHAD, F. IZADI, Application of histomorphological method to assess meat products: A case study, Anatomical Sciences. 13(2):79-84, 2016.

5. MORAR ADRIANA, I. KÁLMÁN, ALEXANDRA PLIC, CLAUDIA CORINA SALA, Quality and safety assessment of meat products obtained by traditional romanian recipes scientific papers. Animal Science and Biotechnologies, 49 (4), 2016.

6. SCHMID ALEXANDRA, SILVIA AMPUERO, U. BÜTIKOFER, D. SCHERRER, R. BADERTSCHER, R. HADORN, Nutrient composition of Swiss cooked sausages. Fleischwirtschaft - Frankfurt -. 24. 61-64 (2009). 